\title{
Performance of SMEs: Special Focus on Small Size Businesses (SSBs) Determinants of Growth at the Tangail using Logistic Regression
}

By Joynab \& Roksana Akhter

Mawlana Bhashani Science and Technology University

Abstract- Small scale enterprises (SMEs) take possession of dominant position in any developing countries like Bangladesh. Small scale enterprises (SMEs) specially focused on the study of Small scale business (SSBs) at tangail which is significant contribution of countries economy where density of population is very high because it offers large number of employment generation opportunities and income generation at low cost which is reduction poverty. Considering the importance this study has strived to identify those were collecting primary data which is statistically significant. First using educational level of entrepreneur's, loan facilities,' sector of loan collecting, employment generation and poverty reduction analyze frequency of statistics and later using logistic regression determinant of gross profits, asset growth at tangail district. The study shows that entrepreneurs of SSBs $82 \%$ influences of profit rising by educational levels and ownership of business is $58 \%$ and $72 \%$ profits rising when loan facilities of SSBs.

Keywords: SME, small size of businesses (SSBs), poverty reduction, logistic regression, predictors' growth.

GJHSS-E Classification: FOR Code: 149999

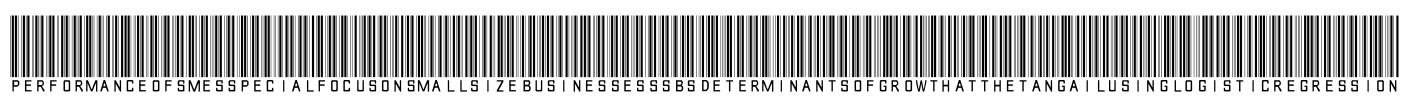

Strictly as per the compliance and regulations of:

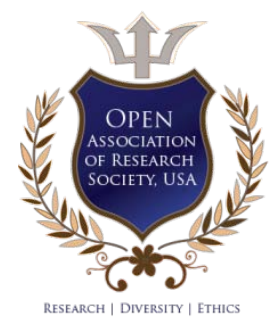

(C) 2020. Joynab \& Roksana Akhter. This is a research/review paper, distributed under the terms of the Creative Commons Attribution-Noncommercial 3.0 Unported License http://creativecommons.org/licenses/by-nc/3.0/), permitting all non-commercial use, distribution, and reproduction in any medium, provided the original work is properly cited. 


\title{
Performance of SMEs: Special Focus on Small Size Businesses (SSBs) Determinants of Growth at the Tangail using Logistic Regression
}

\author{
Joynab $^{\alpha}$ \& Roksana Akhter ${ }^{\sigma}$
}

Abstract- Small scale enterprises (SMEs) take possession of dominant position in any developing countries like Bangladesh. Small scale enterprises (SMEs) specially focused on the study of Small scale business (SSBs) at tangail which is significant contribution of countries economy where density of population is very high because it offers large number of employment generation opportunities and income generation at low cost which is reduction poverty. Considering the importance this study has strived to identify those were collecting primary data which is statistically significant. First using educational level of entrepreneur's, loan facilities,' sector of loan collecting, employment generation and poverty reduction analyze frequency of statistics and later using logistic regression determinant of gross profits, asset growth at tangail district. The study shows that entrepreneurs of SSBs $82 \%$ influences of profit rising by educational levels and ownership of business is $58 \%$ and $72 \%$ profits rising when loan facilities of SSBs. Finally, problems of SSBs profits, asset growth at tangail, and the study conclude on limitation and recommendation those can increase of SSBs profits and asset growth rising of economic development.

Keywords: SME, small size of businesses (SSBs), poverty reduction, logistic regression, predictors' growth.

\section{INTRODUCTION}

S mall and medium-sized enterprises (SMEs) are alternative driving forces of economic growth in any developing country likes Bangladesh. The government and the central bank have taken various initiatives for SMEs. Chairperson of SME foundation K.M Habib ullah said Prorating the SME; among the small entrepreneurs in our country small entrepreneur have greater prospects for generating employment, reducing unemployment and achieving economic growth. At least $40 \%$ of the total disbursement target of SME credit should be reserved for small entrepreneurs and the rest allocated to the medium entrepreneurs. The government has been putting emphasis on the SMEs and taking different measures for its development considering the sector as driving forces to transform the country's huge population into human resources, as it contributes 25\% to the GDP. But the SME entrepreneurs especially women, are still facing difficulties in ruining viable

Author a: Postgraduate in economic. Mawlana Bhashani Science and Technology University, Santosh, Tangail-1902.

e-mail: joynabjothi001@gmail.com

Author 6: Assistant Professor, Department of economic. Mawlana Bhashani Science and Technology University, Santosh, Tangail-1902.

e-mail: roksanaakhterlucky@gmail.com businesses, meanly due to difficult access to finances, high costs and poor infrastructure and marketing facilities. SME sector has the highest opportunity to create employment, in a country like Bangladesh. The SME sector can play a major role as it is great force for the domestic market. But to play the due role, the sector has to provide enough facilities. The problem of SME sector has limited access to the global market. it needs to increase the SME market in the outside world.

Besides, the entrepreneurs have to provide technological support to enhance productivity. The other major obstacles that SME entrepreneurs have been facing are storage of skilled manpower, inadequate training facilities and inadequate access to online ECommerce platforms, the recent data from Bangladesh Bureau of statistics (BBS) shows that the contribution of the industrial sector in the country's GDP was 32.42 percent in 2016-17 while it was 31.54 percent in 201516.but, the contribution of industrial sector in the country's GDP increasing day by day recent year the contribution of industrial sector in GDP is 33.71 percent 2017-2018.

With the $25 \%$ contributions to the country's GDP (SME) have been accelerating the country's industrialization as well as economic growth. Chairperson of SME foundation K.M Habib ullah told the independent that SMEs could play an important role to improve a country's economic growth, as they required minimum capital, generated large employment were easy to start and contribution to export earnings. A percent around 78 lakh jobs have been created in the SME sector. The total number of SMEs in Bangladesh is expected to be 85000 among then over $90 \%$ are small and $7 \%$ medium he said.

In Bangladesh small size of businesses defined as an enterprises would be treated as small if, in current market prices, the replacement cost of plant, machinery and other parts/components, fixtures, support utility, and associated technical services by way of capitalized costs (of turn-key consultancy services, for example), etc. excluding land and building, were to up tk.15 million and it has less than 25 workers, in full-time equivalents.

With the vision of reaching its millennium development goals (MDGs), the government of Bangladesh has given the maximum inclination toward the development of small and medium enterprises 
(SMEs) at all levels in Bangladesh. Now a day it offers the biggest opportunity to create new ventures with new employees. However, it is worth mentionable that SMEs in Bangladesh provide near about its $80 \%$ industrial employment .without any doubt SMEs are in fact the mainstay of the economy of Bangladesh to ensure working opportunities especially for young people and female workers who want to work. Though it suffers from various internal and external problems such as paucity of self-fund, poor knowledge of trade, lack of stability unskilled personal, high burden of interest, lack of transparency and accountability, lack of technology, know how, intense competition, lack of facilities in the field of research and development etc.

Bangladesh owns a history of SMEs in the ancient period. Bengal was rich in different small and cottage industries in those times. Cottage industries in Bangladesh have their roots in the ancient past which included cloth, pottery, carpentry, iron, silver, gold works, preparing paper from bamboos etc. Before British invasion in the Buddhist, Hindu and Muslim regimes those industries developed day by day. During Muslim rule in India, Jamdani, muslin and silk sharee became very popular all over the world. Beside these, in that period, industries related to sugar, salt, and oil production, making of combs and buttons were also important cottage industries.

\section{il. Literature Reviews}

Nagaya (2017) state that the significant of SMEs in economic growth and development, numerous studies have assessed the role of SME sectors in light of various sectors stimulating growth and development. He is also examines the impact of SMEs on the economic growth using data set for India and found that SMEs activities are growth enhancing through various channels like employment and poverty reduction. Aremu and Adeyemi (2011) find similar evidence that SMEs are vital agent in creating job opportunities and reducing poverty.

World bank 2012 report suggests that financial access is vital for the growth and development of SME's in Bangladesh. The availability of external finances impacts of productivity and the growth of this industry. Dhaka chamber of commerce and industries (DCCI) in its economic policy working paper of 2004 enumerate the demand side (lack of collateral, lack of limited business experience, lack of information etc.) and supply side (terms and condition, lack of access to start up finances, availability of funds to banks etc.) the problems in getting access to finances for SME in Bangladesh.

Otugo Nkiru Esther, Edoko Tonna David., and Ezeanolue Uju Scholastica (2018) shows that the title -effect of small and medium enterprises on economic growth in Nigerial it is examine the effect of SME on economic growth in Nigeria. Specially shows that growth rate of Nigeria economy, employment generation growth rate and level of corruption as well as central bank or commercial bank credit facilities which increase SME by raising economic growth rate of Nigeri Acho Yunusa and Abuh A.Paul (2018) show the title -Assessment of the contributions of small scale enterprises to the development of the Nigerian economyll the paper shows the SSB can make profits for the enterprises to survive good and services to the society in order to the society in order to the improve the standard of living of the society and important contribution on the society lead to the growth and development of the economy. an economy.

Sidika Basci and Aysegul Durucan (2017) shows the title -A review of Small and medium sized enterprises (SMEs) in turkeyll state the turkey economic development by SME is increases in growth rate.

Sidika Basci and Aysegul Durucan (2017) shows the title -A review of Small and medium sized enterprises (SMEs) in turkeyll state the turkey economic development by SME is increases in growth rate.

Syed Abidur Rahman and Seyedeh khadijeh taghizadeh-nastaran (2017) shows the -on the road to SME sector development in Bangladesh: A guideline based on current challenges and opportunitiesll. It is shows the economic development some major challenges which is solve by some micro and macro level recommendation on the economic development of Bangladesh.

Above the study literature reviews shows that many different sources of SMEs but this study shows that specially SSBs at tangail. Understanding the relationship among SMEs profit, saving, asset growth, poverty reduction, in macro level have been interested many researcher and there are many attempts to establish statistical relationship. But, still there has been limited work in Bangladesh at micro level to focus only the small size business (SSB) and their contribution for the economic development. So, this study attempts to relationship of profits growth and assed growth by using logistic regression.

\section{a) Objectives of the study}

i. To determinate performance and the accumulation of small scale business (SSBs) relation on asset growth, and profits growth at tangail

ii. To analyze the impact of employment generation and poverty reduction of SMEs investment.

iii. To find out the problem of limitation and recommendation of SMEs at tangail, in Bangladesh.

\section{ili. Methodology}

\section{a) Primary Data collection}

A structured questionnaire was developed on the basis of some valuable indicators to which the respondents were asked to put the right mark against to 
the dichotomous questions and asked to put the quantitative data in the given spaces for monthly data and total years income profit saving and reinvestment capital or capital structure. At the end of each questionnaire it has blank space for mentioning the problems of doing small business and suggesting as well. b) Secondary data collection

The secondary data collection has been collected from ministry of industries, SME foundation, Bangladesh bank (BB), BSCIC,MIDAS, Financial institutions and from other SME related organizations, different books, national and international papers, proceedings, magazines etc.

Sample size distributed by the SSBs as following sectors bellows-

Table 1: Collecting data from different SSBs institution.

\begin{tabular}{ccc}
\hline Valid sectors & Frequency & Percentage \\
\hline Service & 34 & 8.9 \\
Grocery & 91 & 23.7 \\
Handloom & 63 & 16.4 \\
Cottage & 60 & 15.6 \\
Cloth store & 59 & 15.4 \\
Other small business & 77 & 20.1 \\
Total = & 384 & 100 \\
\hline
\end{tabular}

Source: Author construct with data from the SSBs institution

Quantitative sampling technique was then used to select the SSBs sectors. The technique is very useful since it helped to reach targeted samples quickly and also help to get easily the opinions of the target population.

- Profits growth (dependent variable): (positive gross profits growth $=0$ (Yes), decline or no change in growth $=10(\mathrm{No})$ and independent variable nominal or ordinal as, educational level, categories of the sectors, loan facilities ,ownership of business etc.

- Asset growth (dependent variable) :( positive assent growth $=0($ Yes), decrease or change in assed growth $=1$ (No) and independent variable as: educational level, profit of SSBs, Ioan facilities etc.

\section{c) Participants}

Although sample size is unknown, we determine the value of sampling technique use, finally participants of sampling is 384 persons for unknown population, do not any missing values include.

\section{d) Instruments}

Quantitative data was collected from the owners or managers of the sampled SSBs using a questionnaire. The data gather was analyzed with statistical software programs, SPSS software versin.25. The purpose is to combine the advantage of the software programs; data entry, reliability of data by Cohen's kappa measurement technique, frequency statistics, and chi2 data analysis were done in SPSS Versions 25. The data is coded or imported into SPSS software version. 25 are used for the binary logistic regression. also use excel software by secondary data analysis.

e) Procedure and timeline

The procedure of the study is 384 questionnaires deliberated by personal interview of SSBs entrepreneurs at tangail district. The data collection procedure was field work personal interview of SSBs owners at tangail. The data was recorded by questionnaires. Since, I an student, I have no financial ability survive any other procedure to maintain to recording and collecting data. The procedure fill-up data questionnaire and recording and analyzing estimating technique I have six month of date line to complete thesis study.

\section{f) Analysis}

The study of paper shows that SPSS Software using by data entry, manipulation, data reliability test, model specification, and analyzing results of the model. At first introduced of SSBs institution at tangail six categories of SSBs and then entrepreneur's educational levels as well as loan facilities of SSBs or which sector is getting loan of SSBs manufacturer at tangail. it is only shows the statistical software of frequency analysis before using this procedure, analyze crosstab of data reliability of measurement. The data analyze also shows that, data reliability of measurement Cohen's kappa. The value of kappa measurement is refers to p-value which is less than $.05 \%$ and $1 \%$ levels of significant. the study paper also find that logistic regression model which shows predicted profit of SSBs, accumulation of asset growth and saving of SSBs at tangail. I choose 
logistic regression analysis test because of primary data collection it is not tested on homogeneity of degree. The study find the SSBs owner's at tangail any relationship of profit; saving and re-investment of SSBs. Loan facilities of SSBs can positive or negative impact on SSBs at tangail. Before using logistic regression I see chi2 test and Cohen's kappa reliability of measurement. I also find that the value of kappa is $5 \%$ level of significant. so, I hope that, the quantitative data of logistic regression is the perfect model of SSBs sector because of I want to find the relationships of profit saving and re- investment.

\section{g) Ethics and limitation of the study}

The collecting data from primary sources, I would face many difficulties because it is first task collecting data. so there are many problem arising data collection, to maintain SSB entrepreneurs confidentiality they avoid some questions. so, it was quite difficult for me to get in-depth knowledge about some of my task. The time constant is another limitation. The secondary source of collecting data, I do not have sufficient book information, publication and information is not available. Lack of available up to date information, the entrepreneurs have no provide to some internal data which is not strong information about SSB in tangail district, Lacks of previous practical experiences about these topics as I am a newcomers . Lack of In-depth knowledge and analytical ability is writing such report. Only few days' internship report experience is not enough to find out all the limitation of such a vast project.

If these limitations were not been there, the report would have been more useful.

\section{Results Analysis And Discussion}

\section{a) Educational level of entrepreneur}

The study of SSBs at tangail shows that, educational level of entrepreneurs test on frequency test of statistics on SPSS software as following bellows.

Table 2: Education educational level of entrepreneur

\begin{tabular}{ccccc}
\hline & Frequency & Percent & Valid Percent & Cumulative Percent \\
\hline Valid Primary & 242 & 63.0 & 63.0 & 63.0 \\
secondary & 101 & 26.3 & 26.3 & 89.3 \\
higher secondary & 32 & 8.3 & 8.3 & 97.7 \\
Graduate & 9 & 2.3 & 2.3 & 100.0 \\
Total & 384 & 100.0 & 100.0 & \\
\hline
\end{tabular}

The frequency of statistics analysis shows that small scale business (SSB) of tangail total numbers of observation 384 there is no missing values the 100 percent respondent ensure their feedback. The educational levels of entrepreneur are primary levels $63 \%$ and secondary $26 \%$ as well as higher secondary, graduate $8.3 \%$ and $2.3 \%$ respectively. The maximum rate of educational level is primary and secondary levels most of the entrepreneur so that the productivity measured hampers because level of education is low. Small scale business (SSB) entrepreneur is ensured secondary or higher secondary school certificates among the promoters which are rapidly increasing growth rate of SSBs. the benefits of economy when ensure educational level they increase productivity, it is also measure the growth rate of economy by providing tax with raising living standards of entrepreneurs that directly or indirectly tax increasing growth rate of consuming expenditure. The prospects improving SSBs of tangail face many problems. Women are highly participates in SSBs specially (Handicrafts and Handloom) producing at home but most of the women are illiterates or primary level education so they do not increasing a modern or advance level technology used.
They using of old acquaintance or equipment's which are not increasing productions rapidly. so, government ensure raising qualification of man and women in producing SSBs such as: education, infrastructural facilities, bank credits, etc. which increase SSBs at tangail. 
b) Category of small scale business (SSBs)

Table 3: Categories category of the sectors

\begin{tabular}{cccccc}
\hline & & Frequency & Percent & Valid Percent & Cumulative Percent \\
\hline Valid & Services & 34 & 8.9 & 8.9 & 8.9 \\
& Grocery & 91 & 23.7 & 23.7 & 32.6 \\
handloom & 63 & 16.4 & 16.4 & 49.0 \\
Cottage & 60 & 15.6 & 15.6 & 64.6 \\
& cloth store & 59 & 15.4 & 15.4 & 79.9 \\
& 77 & 20.1 & 20.1 & 100.0 \\
& other small business & 384 & 100.0 & 100.0 & \\
Total & &
\end{tabular}

The collection of data is randomly selected by study areas which are selected of six categories of business. The cumulative percentage shows above table of about six categories. The small scale business(SSBs) taken for the studies are service sectors, grocery shops, tea stole, retail and whole sale shop, cottage industries, tangail handloom industries, hard ware shop, stationary, jewelry shop, electronics, furniture's, book house etc. Bellow's the table shows that, frequency of data $8.9 \%$ of the service sectors, 23.7 $\%$ of grocery, $16.4 \%$ of cottage industries, $15.6 \%$ of handlooms, $15.4 \%$ of cloth store, $20.1 \%$ of other small business. c) Loan facilities of SSBS

The bellows table shows that the access to finances of SSBs credit is different way such as nongovt. organization (NGO), private banking, and government banking sectors, or other sources of credit finances by SSBs at tangail. The loan facilities of the SSBs at tangail out of 384 sample excess to finances as 284 other 100 remain do not have loan facilities of their SSBs sectors.

Table 4: Loan Facilities of Business

\begin{tabular}{cccccc}
\hline & & Frequency & Percent & Valid Percent & Cumulative Percent \\
\hline Valid & yes & 284 & 74.0 & 74.0 & 74.0 \\
& No & 100 & 26.0 & 26.0 & 100.0 \\
& Total & 384 & 100.0 & 100.0 & \\
\hline
\end{tabular}

\section{d) Sectors of loan SSBS}

The loan facilities of SSBs at tangail 1.3\% is government banking, $16.9 \%$ is private banking, nongovernment organization(NGO) provide is a large amount of loan facilities $51.3 \%$. other sources of SSBs loan facilities is $15.6 \%$ and no-loan facilities is SSBs of tangail is $14.8 \%$.there are many restriction of getting loan of SSBs, such as: morgues, types of SSBs, roles and regulation of different types organizations, higher interest rate etc., which is discourage to getting loan facilities of SSBs at tangail. If SSBs get access to loan facilities is available than previous regulation is flexible to excess to get credit which is provide more employee opportunities and contribution of economic growth in Bangladesh.

Table 5: Sectors the loan sectors

\begin{tabular}{cccccc}
\hline & & Frequency & Percent & Valid Percent & Cumulative Percent \\
\hline Valid & Govt. banking & 5 & 1.3 & 1.3 & 1.3 \\
& private banking & 65 & 16.9 & 16.9 & 18.2 \\
& NGO & 197 & 51.3 & 51.3 & 69.5 \\
& Others & 60 & 15.6 & 15.6 & 85.2 \\
& No loan facilities & 57 & 14.8 & 14.8 & 100.0 \\
& Total & 384 & 100.0 & 100.0 & \\
\hline
\end{tabular}

Non -government organization (NGO), can provide loan easily or flexible ways SSBs at tangail. It is more improving to SSBs, increasing production which is indicators of re-investment facilities of SSBs sectors. The study of this paper shows that SSBs at tangail is more adequate than other areas such s:cottage 
industries and tangail shares (handloom industries) which is not enough to get loan facilities that he get is restricted on higher interest rate and restriction of morgues, and role regulations of financial institutions which do not increase investment of SSBs at tangail. so, the studies find that government can ensure flexible loan facilities which is increasing investment of SSBs. Government ensure adequate loan facilities of SSBs than it would improve better performance of SSBs. The reasons can help economic development Bangladesh.

e) Impact of employment generation and poverty reduction

Small and medium enterprises (SMEs) have made great contribution of eradicating poverty of Bangladesh economy. SSBs are regarded as the engine of economic growth to any nation's development. The major advantage of this sectors are it ability to employee at low capital cost. The labor industry of the SMEs is much higher than that of the large enterprises. SMEs as a nursery of entrepreneurship are often driven by individual creativity and innovation. The SMEs sector is the engine of economic growth process which is contribute a chains of development of any developing countries like Bangladesh. SMEs of Bangladesh are main drivers of new innovation, job creation, poverty reduction, wealth creation, income distribution and reduction in income disparities, after economic reform on 1986, the SMEs are seen as a key to Bangladesh economy's growth and poverty alleviation and unemployment reduced in the country.
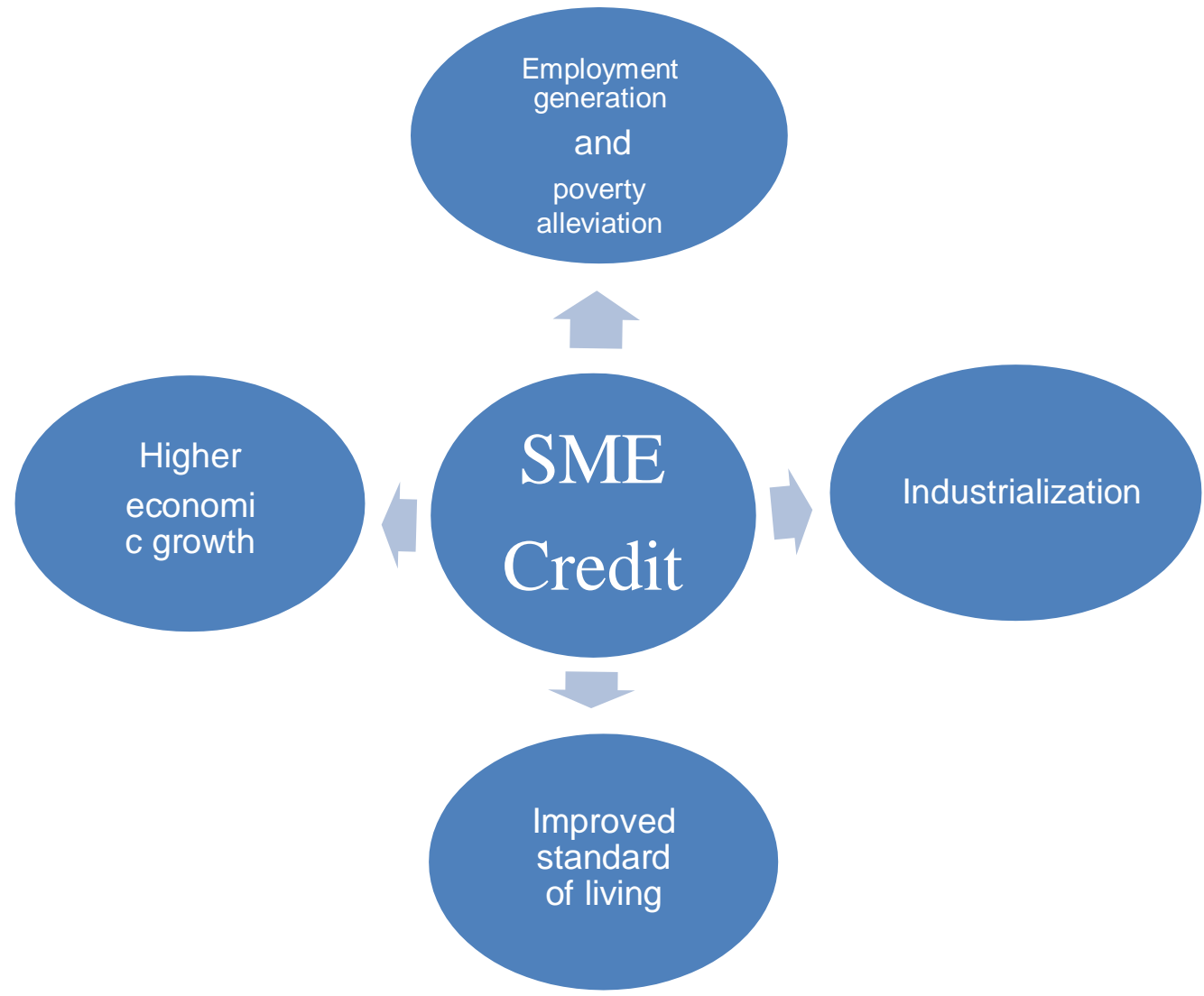

\section{Figure 1: Representation of SME how credit contribution to establish the employment generation and poverty reduction the economy of Bangladesh (author self).}

Therefore, it is need to promotes such SSBs enterprise in any developing countries like Bangladesh because, since SMEs brings about a great distribution of income and wealth, economic self-dependence, entrepreneurial development employment and other positive economic growth of Bangladesh. Awosika (2011), Schmiz (2010), and Aremu (2010) explain that SMEs provides income, saving and employment generation. They are seen as veritable engines for the development of entrepreneurial capabilities and indigenous technology which will generate employment in the country. This study of paper shows that the SSBs entrepreneurs have great contribution on business. Sample of study is 384 which $85 \%$ people is getting SSBs profit gain that provide their living of standard, consumptions pattern changes their raising profits of SSBs at tangail.

\section{The Logitic Regression Model}

- Model specification

These sections explain the development of a model using Logistic regression analysis (Logit). The 
assumption of Logit dependent variable is binary or dichotomous. Taking value 0 when increasing of SSBs and value 1 represent non- increasing of SSBs. The Logit model is a non- linear specification ensure that the predicted probability is $(0,1)$ for all value of $t$ is known as the Logit model.

- Dependent variables

In the binary logistic regression, dependent variable is dichotomous thus, it only contains data coded as 0 (success) or 1 (failure). This paper success and failure were operationally defined as yes and No respectively. Each of the dependent variables is give dichotomous definitions as (by Eva Atu Alhassan)

- Profits growth: (positive gross profits growth $=0$ (Yes), decline or no change in growth $=1$ (No).

- Asset growth: (positive assent growth=0(Yes), decrease or change in assed growth $=1(\mathrm{No})$.

Table 6: Variables Descriptions

\begin{tabular}{ll}
\hline Variables & \multicolumn{1}{c}{ Description } \\
\hline Gross profit growth & Change in profit over time \\
Saving growth & Increase saving rate of over time \\
Asset growth & Acquisition of new assets after accessing profits, saving, \\
& ownership, microcredits \\
Enterprises size & Number of employees \\
Loan profile & Loan receives from different sectors.
\end{tabular}

In Logit regression models, the goal is to predict the chances of dependent variable occurring given values of independent variable(s). To predict the probability of $\mathrm{Y}$, the equation below is transforming to use Logit function.

$$
\mathrm{Y}=\beta \mathrm{o}+\beta 1 \mathrm{X} 1+\beta 2 \mathrm{X} 2+\beta 3 \mathrm{X} 3+\ldots \ldots \ldots \ldots+\beta \mathrm{kXk}
$$

Logit transformation of the probability of event can express as:

$$
\operatorname{Logit}(\mathrm{P})=\ln \left(\frac{\mathrm{P}}{1-\mathrm{P}}\right)=\beta \mathrm{o}+\beta 1 \mathrm{X} 1+\beta 2 \mathrm{X} 2+\beta 3 \mathrm{X} 3+\ldots \ldots \ldots \ldots+\beta \mathrm{kXk}
$$

$\beta \mathrm{O}$, is the model constant.

$\beta 1, \beta 2 \beta 3 \ldots . . . k \mathrm{k}$ are the parameters of the independent variables and the set of independent variables (X1, X2, $\mathrm{X} 3 \ldots \mathrm{Xk})$. The range of logistic regression function is between 0 and 1 , which makes it suitable for use as probability model.

Logit function, Logit (p) is defined as:

$$
\operatorname{Logit}(\mathrm{p})=\ln \left(\frac{\boldsymbol{P}}{\mathbf{1 - P}}\right)
$$

Where

$P$ is the probability that an event will occur and it ranges from 0 and 1 . By taking the exponential of both sides of above Logit ( $p$ ) equation, the equation is rewriting as:

$$
\text { Odds }=\frac{P}{1-P}=e^{\beta o} \times e^{\beta 1 X 1} \times e^{\beta 2 X 2} \times e^{\beta 3 X 3} \times \ldots \times e^{\beta k X k}
$$

\section{a) Logistic regression results on the predictors of profits growth}

The table ( ) shows that set of variables affecting gross profit growth, educational level which is put in charge of the day by day running of the business enterprises had a significant relationship with the growth of profits of the entrepreneur. Specifically, the model revealed that when business run day to day basis the entrepreneurs educational level is primary it is more significant the standard deviation of $X$ value is $98 \%$ increasing profits when entrepreneur is secondary level of education, than other the results is $(b=-.003$, S.E $=0.739, p$-value $=0.047$, odds ratio $=0.97 \%$ std. 98.35). on the other hands, the educational level of entrepreneur is secondary or higher secondary educated the profit of the businessman is large than the graduate or higher educational levels, because of the value is insignificants lower educational levels poor managerial skill and higher educational level problems with high standards of livings. The value is secondary and higher secondary level education persons is $\mathrm{b}=-.498$. $\mathrm{S} . \mathrm{E}=.763$, odds ratio $=.61, \mathrm{p}$-value $=.026, \%$ std. 51.418 and $b=-.242, S$. E..833 odds ratio $=.79$, $\mathrm{p}$-value $=.0845 \mathrm{std}$. 77.15$)$ respectively. The value of primary secondary and higher secondary levels educated entrepreneurs receive more than value of probability. The category of the business size is not more important by increasing profit growth in SSBs which indicates that grocery shops of SSBs and other small scale business is more significant value of SSBs at tangail. The loan facilities of SSBs is likely quite importance of SSBs because of higher rate of interest rate at tangail like, NGO, private banking and other sources of SSBs loan facilities. There are many 
problems of crating loan on SSBs because of loan requirement morgues' is high levels. The increasing profit growth at tangail $(b=-.333, S . D=.275$, $p$-value $=$ 0.44 , odds ratio $=.72$ ) depends on loan facilities. So there are many reasons for getting access to loan of SSBs at tangail. We ensure microcredit on SSBs at tangail in interest rate is flexible than can profits raise on the business of SSBs at tangail. Ownership of the SSBs land is rental or own land is important because of own land improve their productivity by reducing rent cost or infrastructural facilities cost minimize low rate. So, one percent raise in profits increase by less than one percent own and establish their business. SSBs at tangail own land ownership $(b=-2.500, S . E=-2.97, p$-value $=.004$, odds ratio $=.58, \%$ std. of $X 96.95 \%$ ).so, the study shows that, ownership of the business is an important role plays. Productivity of the SSBs sector is less important raising profits of SSBs. the labor and capital intensive business are depend on other reasons to increasing profits. Because the value of odds is greater than one probability of occurring is more than profit raising $(\mathrm{b}=.195, \mathrm{~S} . \mathrm{E}=.233, \mathrm{p}-$ value $=.701$,odds ratio $=1.22, \%$ std. of $X=40.250 \%$ ).

Table 7: Logistic regression results on the predictors of gross profits.

\begin{tabular}{|c|c|c|c|c|c|c|}
\hline & $b$ & S.E. & $p>|z|$ & $\begin{array}{l}\text { Odds ratio } \\
\mathrm{e}^{\wedge} \mathrm{b}\end{array}$ & $\begin{array}{c}\text { \%Std. } \\
X\end{array}$ & $\begin{array}{l}\text { S.D.of } \\
X\end{array}$ \\
\hline $\begin{array}{l}\text { educational level of } \\
\text { entrepreneur }\end{array}$ & & & 3.236 & & .357 & \\
\hline educational level of entrepreneur(1) & -.003 & .739 & $.047^{\star *}$ & $.97^{\star \star}$ & 98.353 & .994 \\
\hline educational level of entrepreneur(2) & -.498 & .763 & $.026^{\star *}$ & $.61^{* \star}$ & 51.418 & .608 \\
\hline educational level of entrepreneur(3) & -.242 & .833 & .084 & .79 & 77.175 & .785 \\
\hline categories of the sectors & & & 9.250 & & 10.995 & \\
\hline categories of the sectors $(1)$ & .259 & .458 & .319 & 1.29 & 57.222 & 1.295 \\
\hline categories of the sectors(2) & -.390 & .368 & 1.128 & .67 & 28.824 & .677 \\
\hline categories of the sectors(3) & .212 & .379 & .313 & 1.24 & 57.590 & 1.236 \\
\hline categories of the sectors $(4)$ & .700 & .372 & 3.537 & 2 & 6.000 & 2.013 \\
\hline categories of the sectors(5) & .312 & .384 & .660 & 1 & 41.657 & 1.367 \\
\hline ownership of the enterprises & & & 1.519 & & 46.788 & \\
\hline ownership of the enterprises(1) & -2.500 & -2.970 & $.004^{\star \star}$ & $.58^{\star \star}$ & 96.959 & .000 \\
\hline ownership of the enterprises(2) & -.285 & .231 & 1.519 & .75 & 21.776 & .752 \\
\hline Ioan facilities of business(1) & -.333 & .275 & $.044^{\star \star}$ & $.72^{\star \star}$ & 57.441 & 1.395 \\
\hline productivity of the business(1) & .195 & .233 & .701 & 1.22 & 40.250 & 1.216 \\
\hline Constant & -1.045 & .822 & 1.619 & .35 & 20.324 & .352 \\
\hline
\end{tabular}

Significant at $1 \%$, significant at.05\%, 
b) Logistic regression results on the predictors of asset growth

The primary levels of education is a major part of continue of SSBs at tangail but the lack of knowledge, no new innovation of technology dot not have any ideas to creating asset savings on SSBs at tangail, but the significant effect on asset growth of is secondary and higher secondary levels of educated entrepreneurs can improve on the asset growth. The value of study time is primary level entrepreneurs are $(b=-.204, S . E=.721, p-$ value $=.050$,odds ratio $=.82, \%$ std.77.75) and secondary and higher secondary entrepreneurs are $(b=-.008$, $\mathrm{p}=.010$, odds ratio $=.99, \%$ of std. $=99.5$, ) above value shows that the odd ratio is less than 1 , when one unit change in asset growth it is significant value measures increasing asset on SSBs at tangail. The value of asset growth on that entrepreneur's is 99\% of odds ratio logistic regression which is important parts of SSBs at tangail. the SSBs at tangail shows that increasing profit of the business and educational level have a great effect on asset growth of SSBs. The loan facilities of SSBs is an significant part because, it is a major contribution of SSBs build on growth which is an area entrepreneur's can get a loan facilities of SSBs financing. The credit facilities of SSBs is narrow sense because higher rate of interest rate, regulation of institutions, and morgues etc. it cannot provide many SSBs entrepreneur's which is not increasing asset growth of SSBs at tangail. The loan facilities of asset growth are hampered on asset growth. The value of odds ratio is 1.19 that is great impact on SSBs growth at tangail. On the other hands, profits and saving rate are an important part of asset growth which can play role of asset growth such as: $(b=-.067$, $\mathrm{S} . \mathrm{E}=.235, \mathrm{p}$-value $=.050$, odds ratio $=.94, \%$ std. 77.54 ) and $\quad(b=-.163, \quad S . E=.230, p-$ value $=.040$, odds ratio $=.849, \%$ std. 87.94 ) respectively. The SSBs owners who are increasing amount of profits that raises to saving on the reinvesting business. so, educational level, ownership of the business, profits and saving which are increasing asset growth on SSBs at tangail positively, but loan facilities are not positive impact on growth of asset on tangail SSBs.

Table 8: Logistic regression results on the growth of gross asset growth.

\begin{tabular}{|c|c|c|c|c|c|c|}
\hline & B & S.E & $p>|z|$ & $\begin{array}{c}\text { Odds ratio } \\
e^{\wedge} b\end{array}$ & $\begin{array}{c}\text { \%Std. of } \\
\mathrm{X}\end{array}$ & $\begin{array}{c}\text { S.D of } \\
X\end{array}$ \\
\hline $\begin{array}{l}\text { educational level of } \\
\text { entrepreneur }\end{array}$ & & & 1.002 & & 80.069 & \\
\hline $\begin{array}{l}\text { educational level of } \\
\text { entrepreneur(1) }\end{array}$ & -.204 & .721 & $.050^{\star *}$ & $.82^{\star \star}$ & 77.759 & .816 \\
\hline $\begin{array}{l}\text { educational level of } \\
\text { entrepreneur(2) }\end{array}$ & .008 & .740 & $.010^{\star \star \star}$ & 1.00 & $99.501^{\star *}$ & 1.005 \\
\hline $\begin{array}{l}\text { educational level of } \\
\text { entrepreneur(3) }\end{array}$ & -.342 & .796 & .184 & .71 & 66.775 & .710 \\
\hline $\begin{array}{l}\text { ownership of the } \\
\text { enterprise }\end{array}$ & & & .492 & & 78.185 & \\
\hline $\begin{array}{l}\text { ownership of the } \\
\text { enterprise(1) }\end{array}$ & -.537 & $\begin{array}{c}40192.96 \\
9\end{array}$ & $.037^{\star \star}$ & .61 & 85.960 & .667 \\
\hline $\begin{array}{l}\text { ownership of the } \\
\text { enterprise(2) }\end{array}$ & -1.293 & .218 & .492 & .37 & 48.296 & .858 \\
\hline $\begin{array}{l}\text { profits of the } \\
\text { business(1) }\end{array}$ & -.067 & .235 & $.050^{* *}$ & $.94^{* *}$ & 77.543 & .935 \\
\hline $\begin{array}{l}\text { the amount of saving } \\
\text { on profits(1) }\end{array}$ & -.163 & .230 & .040 & .849 & 87.946 & 1.177 \\
\hline $\begin{array}{l}\text { loan facilities of } \\
\text { business(1) }\end{array}$ & .173 & .243 & .005 & 1.19 & 94.519 & 1.017 \\
\hline Constant & .717 & .783 & .839 & 2 & 35.958 & 2.048 \\
\hline
\end{tabular}




\section{Vi. Limitations and Recommendations}

a) Statement of the limitation of SSBs in Bangladesh

Despite their critical role in the country, small scale enterprises in Bangladesh has experience high failure rate due to the existences of large scale business enterprises which might serve as a competitive forces to them .Small scale business has been observed to experience high failure rate in Bangladesh due to inadequate finances, lack of technical and managerial manpower. Structural imbalances facing this sector have curbs competitiveness along with the problems. The deficiency approaches and strategic leadership is also significant reason for the failure of small scale enterprise in Bangladesh. One cannot expect an economy to develop and sustained economic growth and development if the environment is not conducive enough for small scale enterprise. Therefore, the study shall appraise the contributions of small scale enterprise to the development of Bangladesh economy.

\section{i. Higher interest rate}

SMEs in the tangail district have safer from many problems in small scale business one of them are higher rate of interest rate. Higher interest rate from micro finances institutions banks is another barrier to SSBs in tangail. Interest rate $16 \%$ to $17 \%$ discourages new SSBs and act as a barrier to the expansion of small scale businesses in tangail.

\section{ii. Paucity of wealth problems}

The Paucity of own founds is major challenge in the small business. They have to either borrow capital/fund personally or from different micro finance or financial institutions. This is a major problem for SSBs in tangail. The survey reveals that among the respondent $87 \%$ strongly agree that paucity of found is major barrier to SSBs in tangail, 13 percent agreed while none of them were indifferent, disagreed or strongly disagreed in this regard.

\section{iii. Lack of financial institutions}

The survey also reveals that lengthy process of getting fund from financial institution is another problem to SBs in tangail. This hampers their growth, 50\% of the respondents strongly agreed, 42\% agreed higher interest rate is another problem in SSBs in tangail, 8\% remained indifferent and none were disagreed of strongly disagreed in the expansion of SSBs in tangail.

\section{iv. Lack of education in SSBs}

The problem faced by SSBs in tangail that graduate and post graduates and post graduates are not interested in SSBs. They always run for better job in the capital city. As a consequence educated people who can implement the business strategy efficiently are not interested in SSBs. So lack of graduates and post graduates in operating SSBs is another problem. That lack of graduates and post graduates is a barrier in SSBs in tangail. Since most of the owners are not graduates, they do not possess the knowledge about marketing strategies. This creates a problem marketing is their product and retaining customers.

\section{v. Lack of Participation of women employees}

Participation of women entrepreneurs in SSBs is not so satisfactory. in SMEs women entrepreneur are taking active part. But in tangail, women's involvement in SSBs is not satisfactory compared with other SMEs and this is also another problem. Competition has been increased among different businesses. SSBs must also compete with other SMEs, and other businesses to gain market share, in tangail the number of SSBs has increased. As a consequence, competition among them (SSBs) and SMEs has increased. Intense competitions among them have led to a problem that to survive they must compete and win.

\section{vi. Lack of transportation facilities}

Transportation facilities are vital for every business enterprise. Products produced by the small scale businesses (SSBs) must be transported to different part of the country and in the hands of consumers. This will increase revenue. For this purpose an efficient transportation network is essential. In tangail, SSBs face the problem of transporting their goods to the customers timely. Poor transportation facility is the reason for this delay. Among the respondent, transportation facilities is the major barrier in tangail district.

\section{vii. Lack of technology}

Technological advancement and technological know- how are essential for modern business. Use of internet, mobile phone, mobile internet, and computers are essential elements for successful business. This requires knowledge as well as expenditure. SSBs does not have sufficient fund to bear these expenses and avail these modern technological services. Nor do they have the expertise or skilled people to avail these services for their business. Net-work coverage is not sufficient in this area. The study reveals that lack of technological knowhow and facility is a problem for SSBs in tangail.

\section{viii. Burden of government rules and regulation}

Government's tax, trade policy and registration fees also hamper the growth and expansion of SSBs in this area. Study reveals that 20 percent of the respondents agreed, 77 percent strongly agreed that government policy sometimes becomes a barrier to small scale business (SSBs) while 3 percent remained indifferent in this regard.

\section{ix. High employee turnover problems}

High employee turnover is the major barrier faced by small scale businesses (SSBs) in the tangail as well as whole Bangladesh. Lack of sustainability, efficiency in operation, unskilled or semi-skilled worker makes these businesses financially insolvent. Because of these employees leave these organizations for agreed that high turnover is problem of SSBs in tangail. 


\section{x. Lack of employee experience}

Small scale business (SSBs) do not have any training facilities of unskilled or semi- skilled labor who are doing in the business. The lacks of experience of SSB are the major problem in tangail. The research paper reveal that 93\% SSBS do not have training facilities and other $7 \%$ agree with the some specific region do have their training facilities of them small scale business (SSBs).

\section{ReCOMmENDATION}

Increasing entrepreneur's education: Entrepreneurship education is one of the important means of development of SME sectors in Bangladesh. Still in the education system the entrepreneurship courses are not been made mandatory. The entrepreneurship education should start from the higher secondary level in the country. Entrepreneurships courses found to be taught only in business related programs in the country. However, it is important for bangladesh. in addition, there should be separate courses as practical, where student need to create an entrepreneurship venture within their institutional premises and run the business for at least one year. Perhaps based on the running the business students will be evaluated in the exam.

Increasing training facilities: Entrepreneurship training facilities programs should be formalized in each district town of the countries likes tangail. Entrepreneurship training programs certification could be pre-requisite to obtain financial assistance for the business. During the training facilities, entrepreneurs should be given information technology related training as well which will increasing their competencies. From the study by Rahman et al (2015b), it has been revealed that strategic competencies are important for small scale business (SSBs).

Creating strong well-built network: There should be creating strong well- built network among the SSBs in Bangladesh. SME foundations of Bangladesh should play an important role to create a network among the SMEs. Unfortunately, still there is no database for the SMEs operating in the country. Such data based would not only assist to build network.

Increasing study incubation center: A study incubation center based on sub sector is important for the development of the SME sector. This incubation center will generate new business ideas for the particular subsector and source for the potential market of the product and services.

To ensure market oriented economy: It is important to ensure market oriented economy is based on the sound legal and regulatory structures for the development of the SME sector in Bangladesh. For SSBs is smooth functioning of the marked economy. Bangladesh needs a sound legal and regulatory structure backed by the rule of law so that existing business can thrive and new businesses can emerge freely.

To create entrepreneurial environment: To create an entrepreneurial environment that is driven by friendly rules and regulation encourages the development of SMEs and the foremost role in this scenario is played by government institutions. Effective government institutions must be open and decentralize their administrative structure which will allow a smooth flow of procedures. The governments of Bangladesh should also be free from corruption and create conditions for all citizens to participate and compete in the market place without too much regulation.

To accelerate export and building favorable conditions for the SMEs with foreign partners: Inspiring SME to accelerate export and building favorable conditions for the SMEs with foreign partners, multiplying goods and service export market. The government of Bangladesh can come up with export promotion-support program, that will enable them meet up extra cost to create linkage with the foreign partners.

\section{Vili. Conclusion}

The study of SSBs growth at tangail in terms of growth in gross profits, and asset growth levels using logistic regression is estimated. The study shows that are operated area are mostly SSBs sectors. The mostly entrepreneurs are no formal education. The predictor's variable relating to those of the owner and entrepreneurs as well as financial institution is considered. The results shows that gross profits of SSBs is raise by loan facilities and educational levels which is not depend on categories of SSBs owner at tangail. Asset growth depends on educational level, profit of SSBs, amount of savings, ownership of SSBs. so, we ensure that SSBs above problem slave than get a major amount of profit which gives reducing poverty by employment generation, living standards, rising saving amount etc. This is increase reinvestment of SSBs, by asset growth. SMEs is an important sources of solution to the unemployment problem when is growing in developing countries like Bangladesh.

\section{BIBLIOGRAPHY}

1. Afolabi, M.O. (2013) - Growth effects of small and medium enterprise (SMEs) financing in Nigeria" journal of African microeconomic review, vol. 3, No. 1.(1-12).

2. Asaolu, A. (2005).॥ Promotion of small scale business and their contribution of small scale business in changing a depressed economyll, retrieved, January 252014 from http:/www.scibd. com/doc/20573358/the-contribution-of-small-scalebusiness-in-changing-a-depressed-economy.

3. Yunusa. A. and PAUL.A.A. (2018). - Assessment of the contributions of small scale enterprises to the 
development of the Nigerian economy" journal of good governance and sustainable development in Africa (JGGSDA), vol.4, No 1, april (2018).

4. Alhassan. E.A. \& Alhassan. A.E. (2016). Determinants of SMEs growth in the tamale metropolis Using logistic regression. researchgate: https://www.researchgate.net/publication/30167481 4.

5. Venkasubramanian. $V$ and ramanakumar. Dr. K.P.V. (2018), - A comparative study on development of small and medium enterprises (SMEs) in Kanchipuram districtll department of mechanical engineering, Sri chandrasekharendra saraswathi viswa mahavidyalaya, enthur, kanchipuram- 631561, tamilnadu, India.
6. Racheal. J.A.C. \& Uju. M.S (2018). Role of small and medium enterprises in poverty eradication in Nigeria. European journal of research and reflection in management science vol.6 No.2, 2018. issn 2056-5992.

7. Rahman. A.S. and Nastaran. S.K.T. (2017). On the road to SME sector development in bangladesh: A guideline based on current challenges and opportunities. researchgate: https//www.research gate.net/publication/313881327.

8. Chowdhury. M. \& Alam. Z. (2017). Factors affecting access to finance of small and medium enterprises (SMEs) of Bangladesh. graduate school of business publication and research. https://tourscholar.toura. edu/gsb-pub/12

\section{Appendix Questionnaire}

What is yours name?

1. Gender---
a. male
b. female
c. others

2. Name of the enterprise/business?

3. Address of the business?

4. Martials status ---
a. married
b. single
c. divorces
d. engaged

5. How many family members of your family?

6. Educational level of owner?

(i)Primary (ii) Secondary (S.S.C) (iii) H.S.C (iv) Graduate

8. What are the categories of the sectors?

(a) Services (b) grocery (c) handloom (d) cottage (d) cloth store (e) other small business

9. Capital structure-

(a) Initial capital amount lace/million taka

(b) Current capital amount -lace/million taka 
10. Is your enterprise established on your own land?
(a) Yes
(b) No
(c) Owned and rent

11. Productivity of the enterprise?
a) Capital intensive
b.) Labors intensive

12. If enterprise is labor intensive, then number of labor?

13. Is the employed manpower skilled?
a. Skilled
b. Semi-skilled
c. unskilled

14. Have any training facilities yours labors?
a.) Agree
b.) Disagree
c.) Neutral
d.) Strongly agree
e.) Strongly disagree

15. How many income earned yours own business?

16. How many cost maintaining your family?

17. How many profits owned your business?

18. What is the amount of saving on profits?

19. Have any loan facilities yours business?
a. Yes
b. No

20 .If yes - which is the sectors?
a. govt. banking
b. commercial banking
c. private banking
d. NGO
e. others

21. How much interest rate of loan?

22. Have any loan requirement to get loan facilities?
a. Yes
b. No 